\title{
A specially designed pillow may be used as treatment for young infants with developmental plagiocephaly
}

\author{
Anna Öhman \\ Department of Paediatrics, University of Gothenburg, Gothenburg, Sweden; anna.ohman@friskispraktiken.com \\ Received 17 October 2013; revised 25 November 2013; accepted 5 December 2013 \\ Copyright (C 2013 Anna Öhman. This is an open access article distributed under the Creative Commons Attribution License, which \\ permits unrestricted use, distribution, and reproduction in any medium, provided the original work is properly cited.
}

\begin{abstract}
Developmental plagiocephaly has increased since the back to sleep campaign and is nowadays a rather common condition in infants. Prevention is the best way to decrease this problem, therefore, tools for treatment are needed. This case description of two children who dropped out from a study of a specially designed pillow indicates that the Mimos pillow may work as the treatment in young infants with developmental plagiocephaly.
\end{abstract}

Keywords: Infants; Developmental Plagiocephaly; Treatment

\section{INTRODUCTION}

Developmental Plagiocephaly (DP) is a condition in which the infant's skull is deformed as a result of prenatal or postnatal external moulding forces to the growing cranium [1,2]. If an infant spends most of the time in supine with the head in the same position, this will lead to flattening of the skull i.e. DP [3-7]. The head grows most rapidly during the first six months of life, specially the first three months; hence the DP can develop very quickly in a newborn [8]. In a recent study, the incidence of DP in infants at 7 to 12 weeks of age was estimated to be $46.6 \%$, however, mostly of a milder type [9]. Risk factors to DP are: to be a first-born child, male, twin, premature, tummy time $<3$ times per day when awake, torticollis and slow achievement of motor milestones [2-7,10-14]. A pilot study investigated a special pillow, Mimos (Figures 1 and 2), which has been designed to prevent DP [15]. The result of the pilot study indicated that the special pillow may reduce the risk of DP, and more infants are currently included in that study.

The families who agreed to participate in this study [15] were after the first assessment randomized to one of two groups: intervention or control group. The diagonals

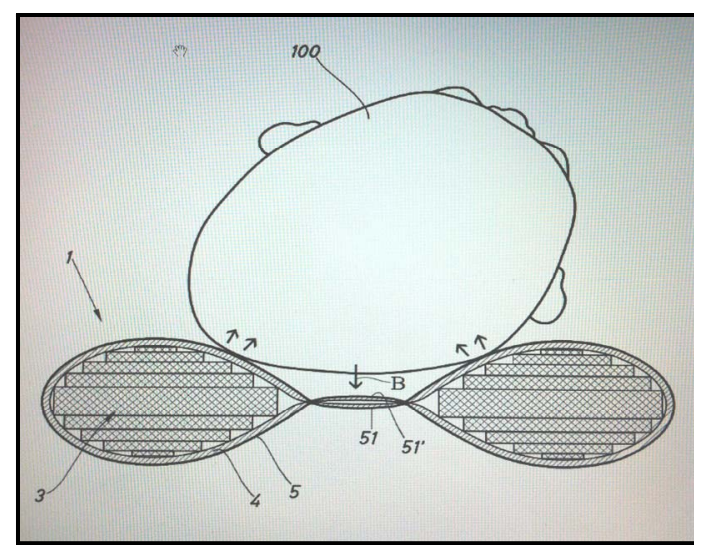

(a)

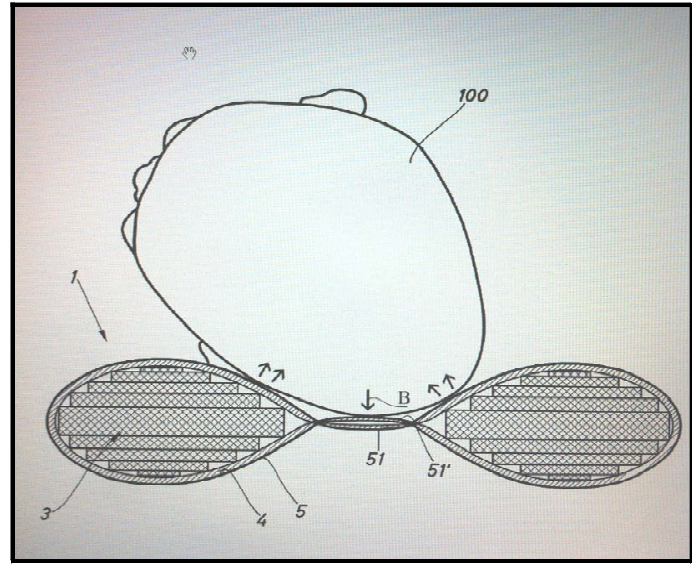

(b)

Figure 1. Showing the function of the special pillow, a cross section. When the infant with plagiocephaly turns the head to the flat side there will be no pressure on this part of the skull (a), if the infant turns the head to the opposite side there is some pressure on the rounded part of the skull (b).

of the head were measured with a craniometer and the Cranial Vault Asymmetry Index (CVAI) was calculated. Zero percent represents equal proportion and a CVAI > 3.5 is considered significant plagiocephaly [16]. The 


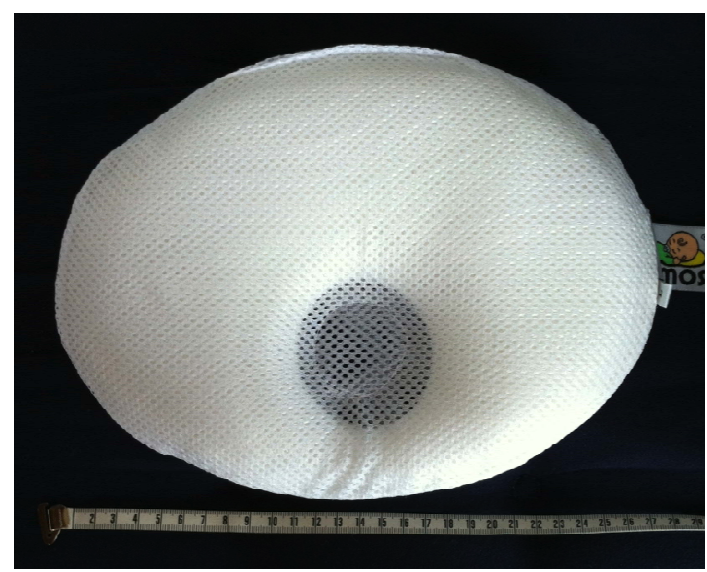

Figure 2. Mimos pillow.

parents were asked about their infant's age, birth weight and length, and week of gestation. Information about the measurements of the diagonals of the head was not revealed to the parents; the head shape was not commented on at all by the examiner. Both groups received written information about why tummy time is beneficial when the infant is awake. On the second/last assessment, the diagonals of the head were measured again, and the infant was also assessed for motor development with SOMP-I [17]. SOMP-I assesses motor function and motor performance. Range of Motion (ROM) of the neck in lateral flexion and rotation was measured, and muscle function in the lateral flexors of the neck and head tilt was examined $[18,19]$. The parents were asked about the infants sleep position and amount of tummy time when awake. The examiner was blinded to group belonging. When the second i.e. last examination was completed, the parents were asked about group belonging.

\section{CASE}

Two infants who were included in a later stage of the study i.e. after the pilot was published [15] were unsuccessful participants because they did not use the pillow as expected. These infants were followed up because they had significant DP. These two children were both randomized to the intervention group, and were given a specially designed pillow (Mimos). The parents were expected to use this pillow every time when the infant was in a supine position, this included use during sleep. For some reason they did not use the pillow as expected, both only used it for short periods in the daytime in the pram. Both had significant DP when they were included in the study at one month of age (Table 1). When they came for the second and last assessment in the study at three months of age, one of them had persistent CVAI and one had increased CVAI (Table 1). Both infants fulfilled several of the risk factors for DP; both were first-born children, male, had tummy time $<3$ times per day when awake and slow achievement of motor milestones. Both infants were born at term and had normal birth weight, there were no signs of torticollis (Table 2).

Despite the fact that the DP was rather obvious in both infants at the start of the study the parents did not seem to have taken it in fully. They had noted that their infants had a flattened head, but could not explain why they chose not to use the special pillow as expected. They said "it just happened". There was no reason to press the parents at this point, instead they received information about DP and that it is not expected to disappear spontaneously. The study did not include further assessments for these infants, however they were asked to attend for a follow up one month later. During the month between the last assessment and the follow up they were asked to always use the special pillow when the infants were in a supine position. The parents were now more aware that they had to act to minimize the DP. At the follow up they reported that their infants had used the special pillow as expected. At the follow up both infants had a decreased CVAI with a decrease of about 3.3 each (Table 1).

\section{DISCUSSION}

In the study the last assessment was scheduled to take place when the infants were three months of age [15]. This age was chosen for ethical reasons; if any infant had DP at the beginning or developed DP during the study there would still be time to use contra positioning techniques to achieve a symmetrical head following the last assessment. An opportunity arose to investigate if ongoing use of the special pillow could decrease DP as the two children who dropped out were not older than three months of age on the last assessment of the study. With a follow up at four months of age there would still be time to change the strategy if no improvement of head shape had occurred during the month between the end of the study and the follow up.

Written information about the advantage of tummy

Table 1. Showing cranial vault asymmetry index CVAI at the two assessments in the study and at the assessment of the follow up at four months of age.

\begin{tabular}{cccc}
\hline & $\begin{array}{c}\text { CVAI at the first assessment at the } \\
\text { age of one month }\end{array}$ & $\begin{array}{c}\text { CVAI at the second assessment } \\
\text { at the age of three months }\end{array}$ & $\begin{array}{c}\text { CVAI after using Mimos Pillow for } \\
\text { one month (at the age of four months) }\end{array}$ \\
\hline Infant I & 5.5 & 8.3 & 4.9 \\
Infant II & 6.0 & 5.7 & 2.4 \\
\hline
\end{tabular}


Table 2. Basic information about the two infants included.

\begin{tabular}{ccc}
\hline & Infant I & Infant II \\
\hline Age at follow-up & 4 months & 4 months \\
Birth weight & 3312 gram & 4180 gram \\
Birth length & $50 \mathrm{~cm}$ & $52 \mathrm{~cm}$ \\
Week of gestation & 40 weeks 1 day & 40 weeks 2 days \\
$\begin{array}{c}\text { SOMP-IT scores at three } \\
\text { months of age }\end{array}$ & 25 & 27 \\
\hline
\end{tabular}

time was given during the study, however both children who dropped out had spent little time in prone, no more than maximum 1 - 2 times a day. Little time spent in prone when awake is associated with low motor performance [20,21]. This was also true for the two infants that scored low on the SOMP-I.

The back to sleep campaign has resulted in a successful decrease in sudden infant death syndrome (SIDS). There is no doubt that infants ought to sleep on the back as this has saved lives [22]. The bi-effect with increased DP has to be dealt with in other ways; education of parents, handling, tummy time and when an infant refuses to vary the head position the special pillow could be used. However whatever method is used it is important to assess that it works. Not all infants behave exactly the same, some are very placid and some are very active, not all methods work for everyone. The nurses who see the infants in clinic and in the health care centers (all healthy infants attend these centers in Sweden) have a great opportunity to help the parents in assessing head shape and give advice on prevention and treatment.According to two studies the use of the pillow does not increase the risk for SIDS as long as the infant is placed and stays in supine when using the pillow [23,24]. However, if the infant sleeps in prone with a pillow this increases the risk for SIDS [24]. Pillows should not be used after an infant starts to turn over to a prone position. There are a lot of pillows available where it is claimed that they can reduce the risk of DP, however there is a lack of evidence for this.

\section{CONCLUSION}

The case with these two infants indicates that the specially designed pillow (Mimos) could be used as treatment for plagiocephaly in young infants. A larger study is needed to confirm or reject if there is a treatment effect.

\section{REFERENCES}

[1] Clarren, S.K. (1981) Plagiocephaly and torticollis: Etiology, natural history and helm treatment. Journal of Pedi- atrics, 98, 92-95.

http://dx.doi.org/10.1016/S0022-3476(81)80549-5

[2] Littlefield, T.R., Kelly, K.M., Pomatto, J.K. and Beals, S.P. (2002) Multiple-birth infants at higher risk for development of deformational plagiocephaly: II. Is one twin at greater risk? Pediatrics, 109, 19-25. http://dx.doi.org/10.1542/peds.109.1.19

[3] McKinney, C.M., Cunningham, M.L., Holt, V.L., Leroux, B. and Starr, J.R. (2009) Case-control study of infant, maternal and perinatal characteristics associated with deformational plagiocephaly. Paediatric and Perinatal Epidemiology, 23, 332-345. http://dx.doi.org/10.1111/j.1365-3016.2009.01038.x

[4] Hutchison, B.L., Thompson, J.M. and Mitchell, E.A. (2003) Determinants of nonsynostoticplagiocephaly: A casecontrol study. Pediatrics, 112, e316. http://dx.doi.org/10.1542/peds.112.4.e316

[5] Hutchison, B.L., Hutchison, L.A.D., Thompson, J.M.D. and Mitchell, E.A. (2004) Plagiocephaly and brachycephaly in the first two years of life: A prospective cohort study. Pediatrics, 114, 970-980. http://dx.doi.org/10.1542/peds.2003-0668-F

[6] Van Vlimmeren, L.A., van der Graaf, Y., Boere-Boonekamp, M.M., L’Hoir, M.P., Helders, P.J. and Engelbert, R.H.H. (2007) Risk factors for deformational plagiocephaly at birth and at seven weeks of age: A prospective cohort study. Pediatrics, 119, e408-e418. http://dx.doi.org/10.1542/peds.2006-2012

[7] Oh, A.K., Hoy, E.A. and Rogers, G.F. (2009) Predictors of severity in deformational plagiocephaly. Journal of Craniofacial Surgery, 20, 685-689. http://dx.doi.org/10.1097/SCS.0b013e318193d6e5

[8] Brofin, D.R. (2001) Misshapen heads in babies: Position or pathology? The Ochsner Journal, 3, 191-199.

[9] Mawji, A., Vollman, A.R., Hatfield, J., McNeil, D.A. and Sauvé, R. (2013) The incidence of positional plagiocephaly: A cohort study. Pediatrics, 132, 298-304. http://dx.doi.org/10.1542/peds.2012-3438

[10] Peitsch, W.K., Keefer, C.H., LaBrie, R.A. and Mulliken, J.B. (2002) Incidence of cranial asymmetry in healthy newborns. Pediatrics, 110, e72. http://dx.doi.org/10.1542/peds.110.6.e72

[11] Joganic, J.L., Lynch, J.M., Littlefield, T.R. and Verrelli, B.C. (2009) Risk factors associated with deformationalplagiocephaly. Pediatrics, 124, e1126-e1133. http://dx.doi.org/10.1542/peds.2008-2969

[12] Hutchison, B.L., Stewart, A.W. and Mitchell, E.A. (2009) Characteristics, head shape measurements and developmental delay in 287 consecutive infants attending a plagiocephaly clinic. Acta Paediatrica, 98, 1494-1499. http://dx.doi.org/10.1111/j.1651-2227.2009.01356.x

[13] Golden, K.A., Beals, S.P., Littlefield, T.R. and Pomatto, J.K. (1999) Sternocleidomastoid imbalance versus congenital muscular torticollis: Their relationship to positional plagiocephaly. Cleft Palate-Craniofacial Journal, 36, 256-261. http://dx.doi.org/10.1597/1545-1569(1999)036<0256:SIV CMT>2.3.CO;2 
[14] Rogers, G.F., Oh, A.K. and Mulliken, J.B. (2009) The role of congenital muscular torticollis in the development of deformational plagiocephaly. Plastic and Reconstructive Surgery, 123, 643-652.

http://dx.doi.org/10.1097/PRS.0b013e318196b9be

[15] Öhman, A. (2013). A pilot study, a specially designed pillow may prevent developmental plagiocephaly by reducing pressure from the infant head. Health, 5, 32-37. http://dx.doi.org/10.4236/health.2013.56A2006

[16] Loveday, B.P. and de Chalain, T.B. (2001) Active counterpositioning or orthotic device to treat positionalplagiocephaly? Journal of Craniofacial Surgery, 12, 308-313. http://dx.doi.org/10.1097/00001665-200107000-00003

[17] Persson, K. and Strömberg, B. (1995) Structured observation of motor performance (SOMP-I) applied to neonatally healthy fullterm infants at the ages of 0-10 months. Early Human Development, 40, 127-143. http://dx.doi.org/10.1016/0378-3782(94)01598-J

[18] Öhman, A. and Beckung, E. (2008) Reference values for range of motion and muscle function in the neck-in infants. Pediatric Physical Therapy, 20, 53-58. http://dx.doi.org/10.1097/PEP.0b013e31815ebb27

[19] Öhman, A., Nilsson, S. and Beckung, E. (2009) Validity and reliability of the muscle function scale, aimed to assess the lateral flexors of the neck in infants. Physiotherapy Theory and Practice, 25, 129-137. http://dx.doi.org/10.1080/09593980802686904

[20] Majnemer, A. and Barr, R.G. (2006) Association between sleep position and early motor development. Journal of Pediatrics, 149, 623-629. http://dx.doi.org/10.1016/j.jpeds.2006.05.009

[21] Salls, J.S., Silverman, L.N. and Gatty, C.M. (2002) The relationship of infant sleep and play positioning to motor milestone achievement. American Journal of Occupational Therapy, 56, 577-580. http://dx.doi.org/10.5014/ajot.56.5.577

[22] Wennergren, G. (2004) Prevention of sudden infant death syndrome. Pediatric Pulmonology, 26, 110-111. http://dx.doi.org/10.1002/ppul.70072

[23] McGarvey, C., McDonnell, M., Chong, A., O’Regan, M. and Matthews, T. (2003) Factors relating to the infant's last sleep environment in sudden infant death syndrome in the Republic of Ireland. Archives of Disease in Childhood, 88, 1058-1064. http://dx.doi.org/10.1136/adc.88.12.1058

[24] Thompson, J.M., Thach, B.T., Becroft, D.M. and Mitchell, E.A. (New Zealand Cot Death Study Group) (2006) Sudden infant death syndrome: Risk factors for infants found face down differ from other SIDS cases. Journal of Pediatrics, 149, 630-633. http://dx.doi.org/10.1016/j.jpeds.2006.07.041 